\title{
Carreira acadêmica: paradoxos e tensões a partir das lentes de gênero e geração
}

\author{
RESUMO
}

lolanda Pinto de Faria E-mail:

iolandapintodefaria@hotmail.com Universidade Federal da Bahia,

Salvador, Bahia.

\begin{abstract}
A idade é importante variável para o mercado de trabalho, sendo, em regra, privilegiada a adultez enquanto fase da vida na qual o sujeito está plenamente apto ao ingresso e à permanência nos espaços ditos produtivos. Entretanto, isso não se dá de modo homogêneo, havendo carreiras, como a acadêmica, que trazem especificidades, valorizando mais ou menos a presença de pessoas velhas. Nesse sentido, com o objetivo de analisar como se dá o alargamento da faixa etária no exercício da carreira docente, esse artigo se debruçará sobre os dados produzidos a partir dos Relatórios de Gestão 2017 das unidades da Universidade Federal da Bahia, que registraram parte dos/as professores/as que participam do Programa Especial de Participação de Professores Aposentados, instituído pela Resolução n. 4/96. Esses dados apontam para a continuidade do/a pesquisador/a na Instituição, mesmo após a velhice, por conta da importância do capital científico, diretamente relacionado com o reconhecimento.
\end{abstract}

PALAVRAS-CHAVE: Carreira acadêmica. Docência. Geração. Velhice. Campo Científico. 


\section{INTRODUÇÃO}

Estudos que cruzam "mercado de trabalho" e "geração" comumente apontam para a marginalização das pessoas com o aumento da idade (GRÜN, 1999; PEÇANHA, 1991), isso porque há uma pressuposição da fase adulta como aquela na qual o indivíduo atinge sua plenitude, seja física, emocional ou racionalmente, sendo, portanto, socialmente valorizada, especialmente no campo profissional (BRITTO DA MOTTA, 2012b; SCOTT, 2001; MÜLLER, 2009). Entretanto, esse trabalho almeja analisar o envelhecimento de docentes de instituições públicas de ensino superior, carreira na qual há especificidades que borram essa regra, sendo comum o reconhecimento de profissionais que compõem a categoria dos velhos, aqui intencionalmente grafada no masculino, em referência às desigualdades de gênero que marcam a academia, fazendo com que o reconhecimento se dê diferentemente entre velhos e velhas.

Ainda que o envelhecimento, a princípio, tenha uma conotação diferente na carreira acadêmica, haja vista que a ideia de acúmulo de conhecimento com o passar do tempo faz com que os velhos gozem de relativo prestígio que não vemos em outras profissões, é preciso ressaltar que isso não se dá sem uma série de recortes. Isso é, a autoridade da qual os velhos desfrutam na docência é atravessada pela classe, pela raça, pelo gênero e, também, pela geração, não sendo, pois, prerrogativa de todos os idosos fugir dos estereótipos de senilidade, vulnerabilidade, caduquez, adoecimento etc.

Ademais, destaque-se que esse trabalho é fruto de um primeiro momento da pesquisa à qual venho me dedicado sobre a carreira docente de mulheres e, por isso, serão analisadas as categorias gênero e geração, sem o aprofundamento devido às categorias raça/etnia e classe social. Essa limitação se dá por ser uma reflexão teórica esteada nos dados produzidos a partir dos Relatórios de Gestão exercício de 2017 de cada uma das unidades da Universidade Federal da Bahia (UFBA), dos quais não é possível extrair uma análise satisfatória das categorias aqui parcialmente descuidadas. Nesse sentido, apontamos, também, para os alcances restritos de um estudo que não abranja o trabalho de campo com diálogo direto com os sujeitos da pesquisa (BRITTO DA MOTTA, 2005), mas cujos achados guiam o longo caminho a ser percorrido.

Dito isso, na primeira parte, será discutida a relevância da categoria geração para estudos nas Ciências Sociais, destacando suas potencialidades quando analisada de modo não meramente descritivo e articulada com outras categorias. Em um segundo momento do texto, será estudado, brevemente e a partir das lentes de gênero e geração, o cenário preponderante das carreiras profissionais para, por fim, relacionar esses dados teóricos com os empíricos produzidos a partir dos Relatórios de Gestão 2017 das unidades da UFBA, numa terceira parte desse artigo, utilizando os conceitos bourdieusianos de capital e autoridade científicos.A introdução deve conter a motivação para a pesquisa, o objetivo e a metodologia aplicada na realização da pesquisa.

\section{DESVELANDO A CATEGORIA ANALÍTICA GERAÇÃO}

A realidade social é complexa, sendo composta por muitas dimensões imbricadas, que se articulam, gerando tensões e relações de poder desequilibradas e hierárquicas. Para dar conta dessa complexidade, a Ciência, em especial as 
Ciências Sociais, têm se utilizado, a partir de diversas propostas epistemológicas, da interseção de mais de uma categoria de análise, mormente classe, raça/etnia e gênero, a partir da compreensão de que nenhum desses sistemas de relações, isoladamente, é suficientemente elucidativo (BRITTO DA MOTTA, 1999; MACÊDO, 2010). Geração, contudo, não é uma categoria que goza do mesmo prestígio, ou status, no meio acadêmico; tem sido utilizada sem que seja contemplada a sua potência enquanto ferramenta de análise das estruturas das relações de opressão.

Inobstante geração ser categoria fundamental para a apreensão de muitos objetos das Ciências Sociais, muitas vezes é negligenciada por uma série de estudos que se enriqueceriam com a análise do par idade/geração, mas que contemplam outras categorias sem se darem conta das discussões geracionais que atravessam seus objetos. Em outros casos, quando essa categoria é contemplada, ela é, geralmente, tratada de modo meramente descritivo, no qual uma das gerações é analisada isoladamente, "[...] como uma espécie de unidade desconectada de outras gerações e de seu tempo histórico" (BRITTO DA MOTTA; WELLER, 2010, p. 175). Outra característica também importante é que os poucos trabalhos das Ciências Sociais que se debruçam sobre geração o fazem a partir do estudo da juventude, havendo uma "[...] escassa atenção teórica e política dada aos velhos [...]" (BRITTO DA MOTTA; WELLER, 2010, p. 180), mesmo nos estudos com enfoque feminista.

Nesse sentido, é paradoxal que a categoria geração seja amplamente utilizada no cotidiano, tendo acepções diversas, desde a relacionada ao verbo gerar à que faz referência a etapas do progresso técnico, como "esse computador é de última geração" (BRITTO DA MOTTA, 2005), e não receba a atenção devida no campo acadêmico. No âmbito das ciências sociais, por exemplo, três são os sentidos principais: a) na referência estatística-demográfica, coorte geracional é um conjunto de indivíduos nascidos em um mesmo intervalo de tempo; b) na tradição antropológica, como gerações na família ou idades biossocial para aquisição de direitos e deveres; e c) no sentido plenamente sociológico, ou geração propriamente dita, é um coletivo de indivíduos que vivem em determinada época ou tempo social e que têm aproximadamente a mesma idade (ATTIAS-DONFUT, 1988 apud BRITTO DA MOTTA, 2005 e BRITTO DA MOTTA, 2010).

Para Alda Britto da Motta (2010), os múltiplos significados do termo é um forte motivo para que essa categoria seja pouco estudada, mesmo sendo, em articulação com classe, raça e gênero, uma das dimensões mais básicas das relações sociais. Além desse obstáculo, "[...] a relativa escassez de contribuições teóricas" (MACEDO, 2010, p. 184) e a variabilidade das posições etárias e dos grupos de idade ao longo da vida de um mesmo sujeito (BRITTO DA MOTTA, 2005) afastam um estudo qualificado da categoria geração dentro da academia.

Na vida vivida, se somos sempre pessoas de um determinado sexo/gênero, raça/etnia e classe social, mudamos de idade - processo biossocial - e de expectativas sobre ela, a cada ano, ao mesmo tempo em que o nosso grupo etário vai assumindo posições geracionais diversas enquanto coorte geracional - embora não necessariamente enquanto geração social no sentido estrutural definido por Karl Mannheim (1928). O jogo de poder entre as gerações se desloca e se reinstala continuamente, causando a impressão de ausência de capacidade estruturante do social... (BRITTO DA MOTTA, 2010, p. 227). 
Ocorre que, por serem relacionais ou da experiência, todas as categorias supracitadas expressam diferenças, oposições, hierarquias e conflitos provisórios entre indivíduos ou grupos (BRITTO DA MOTTA, 2005). Se é bastante fácil entender a provisoriedade da categoria geração, por conta da sua própria natureza, é preciso pensar que as outras também não são absolutas, podendo o lugar social do sujeito se modificar, por exemplo, com o deslocamento geográfico. Assim, uma pessoa que é lida racialmente como branca no Brasil poderá ser "racializada" como latina no Estados Unidos. Isso se dá porque "[...] o conhecimento de cada uma dessas categorias remete, sempre, a uma análise de relações de poder." (BRITTO DA MOTTA, 2005, p. 14).

Desse modo, sexo, idade e cor são inscritos no corpo e na cultura e compõe categorias biossociais de gênero, geração e raça, cujos elementos biológicos são frequentemente utilizados para qualificar e hierarquizar os sujeitos/grupos, "naturalizando" aspectos que são sociais e ideológicos. A análise de cada uma dessas categorias remete, pois, a uma análise de relações de poder e isso foi historicamente feito em relação à categoria classe, sem suas conexões com gênero, raça, geração etc. É só a partir das décadas de 60 e 70 que os diversos segmentos sociais, como mulheres, negros/as e jovens, organizam-se em contraposição aos discursos dominantes, tendo o segmento social dos/as velhos/as "ganhado corpo" apenas mais recentemente (BRITTO DA MOTTA, 2005).

Entretanto, como já apontado, é necessário destacar que não se vive apenas uma dessas dimensões por vez, mas algumas delas de modo simultâneo. Assim, a experiência de cada sujeito é resultante dessa múltipla pertinência social, pois "[...] ser jovem ou ser velho é uma situação/experiência vivida em parte homogeneamente em parte diferencialmente, segundo o gênero, a etnia e a classe social dos indivíduos de cada grupo etário" (BRITTO DA MOTTA, 2005, p. 15). Isso posto, advogar pelo uso da categoria geração como estruturante na construção das relações sociais (SARMENTO, 2005) é defender, também, que esse estudo se dê de modo articulado com as outras categorias já amplamente sistematizadas.

Nesse sentido, para Manuel Jacinto Sarmento (2005), é preciso que se resgate o conceito de geração dentro do contexto complexo no qual essa categoria se insere, haja vista que

[...] a geração não dilui os efeitos de classe, de género ou de raça na caracterização das posições sociais, mas conjuga-se com eles, numa relação que não é meramente aditiva nem complementar, antes se exerce na sua especificidade, activando (sic) ou desactivando (sic) parcialmente esses efeitos. (SARMENTO, 2005, p. 363).

Desse modo, destacando o seu pioneirismo dentro da Sociologia, é preciso avançar sobre o conceito de geração sistematizado por Karl Mannhein (s.d., p. 137, grifos do autor). Embora afirme que "[...] o fenómeno social 'geração' nada mais representa do que uma espécie particular de identidade de posição, que compreende 'grupos de idade' mergulhados num processo histórico-social", o autor dá ênfase ao sentido histórico da categoria (BRITTO DA MOTTA, 2005; SARMENTO, 2005). Ocorre que a construção histórica de uma geração, e aqui estendemos o posicionamento de Sarmento (2005) quando se refere especificamente à infância, se dá em processo longo, tenso, contraditório e contínuo, atribuindo a ela um lugar na sociedade, um estatuto social, com bases normativas e ideológicas. Por isso, é 
[...] possível a reconstrução do conceito de "geração", considerando, para além das suas dimensões externas e internas e de variável independente ou dependente, os elementos sincrónicos (sic) e diacrónicos (sic) presentes na respectiva construção social. O objetivo é "historicizar o conceito de geração, sem perder de vista as dimensões estruturais e interacionais". (SARMENTO, 2005, p. 365, grifos do autor).

É nesse sentido que Sarmento (2005) traz que vários são os fatores constitutivos desse processo, desde as relações econômicas, as políticas públicas e as transformações demográficas, até as práticas sociais, o estilo de vida e os dispositivos simbólicos. Ressalta, também, que "A variação de todas essas dimensões é assíncrona, isto é, não decorre sempre no mesmo sentido, sendo diferente, em cada momento, o peso de cada uma das variáveis em presença." (SARMENTO, 2005, p. 366). Ainda assim, idades e gerações são fatores relevantes de organização social, sendo a condição etária, em especial o envelhecimento, mecanismo fundamental de classificação dos indivíduos (BRITTO DA MOTTA, 2005).

Postas essas premissas e ratificada a importância da categoria geração, é notória a estreita relação desta com mercado de trabalho ou, mais especificamente, com as carreiras profissionais, sendo uma das categorias das quais não se prescinde para uma reflexão teórica do tema. Atendendo à proposta desse trabalho, as análises estarão centradas, também, na perspectiva de gênero, haja vista que "[...] as gerações têm dois sexos, e experiências sociais e trajetórias de vida de homens e de mulheres jamais coincidiram." (BRITTO DA MOTTA, 2005, p. 19). Esse recorte não significa, todavia, um apagamento das categorias classe e raça/etnia, igualmente importantes, mas que serão aprofundas em momento ulterior da pesquisa.

\section{CARREIRA ACADÊMICA: TRABALHO PARA (POUCOS) IDOSOS}

No contexto de um sistema capitalista, participar ativamente do mercado de trabalho, ou seja, ser "produtivo", é central para determinar a posição do sujeito nas tramas das relações sociais. A delimitação dos indivíduos aptos a ocupar esse restrito e privilegiado espaço se dá de modo heterogêneo a depender da carreira profissional, mas sempre de modo complexo, entrelaçando diversos sistemas de opressão, relacionados à raça ou à etnia, ao gênero, à classe e à geração, além de outros. A partir disso, constrói-se estereótipos que marcam a inaptidão daqueles/as que são considerados/as "outros" e que serão cada vez mais afastados/as do mercado de trabalho por sua condição de alteridade.

Com os/as idosos/as não é diferente. Se, por um lado, o envelhecimento da população recebe tratamento institucional e estatal ambíguo, ora protecionista, ora como algo a ser temido, por outro, é visto com interesse enquanto mercado consumidor (BRITTO DA MOTTA,1999). Nesse embate, e também como resultado da longevidade, fica ainda mais evidente que há um grupo bastante heterogêneo de velhos/as, desde as avós que assumem os cuidados com a casa e com os/as netos/as para que suas/seus filhas/os possam estudar e trabalhar àqueles/as que voltam os cuidados para si e incluem na rotina diversos afazeres, como atividade física, viagens, grupos de dança, dentre outros (BRITTO DA MOTTA, 2012a). Ademais, como se pode inferir, essa dissemelhança é atravessada pelos muitos 
marcadores já mencionados, quais sejam, gênero, classe, raça/etnia, orientação sexual, maternidade/paternidade e, ainda, localização geográfica dos sujeitos.

Numa perspectiva de idade/geração, ser jovem ou ser velho é uma "situação" vivida, em parte, homogeneamente e, em parte, diferencialmente segundo o gênero e a classe social dos indivíduos de cada grupo etário. Na perspectiva de gênero, a trajetória de vida de homens e mulheres, como construção social e cultural, vem determinando diferentes representações e atitudes em relação à condição de velho/a. Dessa forma, gênero e idade/geração são dimensões fundantes de análise da vida social. Expressam relações básicas, por onde se (entre)tecem subjetividades, identidades e se traçam trajetórias. (BRITTO DA MOTTA, 1999, p. 207).

Entretanto, no tocante à homogeneidade da experiência de geração, um dos pontos mais marcantes é que os/as velhos/as são, de modo geral, vistos como inaptos/as às atividades profissionais. Ainda que haja uma notória busca por um "envelhecimento bem sucedido", engajado num processo de juvenilização de todas as idades (BRITTO DA MOTTA, 2012b), há uma série de estereótipos que recaem sobre o corpo e a mente dos/as velhos/as, ultrapassando os louros da experiência e acirrando os conflitos entre as gerações nos espaços laborais (GRÜN, 1999; PEÇANHA, 1991). É nesse contexto que os/as idosos/as são "escanteados/as" do mercado de trabalho sob as justificativas de que são desatualizados/as, fisicamente fracos/as, não possuem memória confiável etc., inclusive com respaldo acadêmico. De acordo com a precisa crítica de Britto da Motta (2005), ao defender a importância e a atualidade da temática do envelhecimento, as produções sobre geração, embora em número razoável, pouco contemplam os/as velhos/as. Em geral, retratam o senso comum e não pesquisas científicas ou, em outros casos, são trabalhos médicos que reforçam o estereótipo da velhice relacionada a doenças e a perdas radicais.

A construção dessa imagem de velhice, segundo Remi Lenoir (1998), se dá há bastante tempo, desde meados do século XIX, e não está localizada no Brasil, sendo diretamente relaciona ao sistema capitalista.

\footnotetext{
A "velhice" como problema social surgiu, antes de tudo, na classe operária pelo fato da extensão rápida, sobretudo a partir de meados do século XIX, da organização capitalista do trabalho e do sistema de atitudes que lhe está associado. [...] A "velhice" dos operários é, então, assimilada, pelo patronato capitalista, à "invalidez", isto é, à "incapacidade para produzir" [...] (LENOIR, 1998, p. 79, grifos do autor).
}

É nessa lógica, ou sob esse fundamento, que a fase adulta ganha destaque quando estruturamos, a partir de geração, a análise de determinado problema social. Explico. A adultez é tida como o momento no qual o sujeito adquire sua plenitude, sendo, não coincidentemente, lida como a fase mais produtiva da vida. Isso faz com que, por exemplo, haja um movimento por meio do qual as mais diversas gerações convirjam para essa fase de plena experiência social, fenômeno denominado por Britto da Motta (2012b) de "juvenilização" das idades, no qual as crianças são adultizadas e os/as idosos/as são juvenilizados/as e ambos se encontram e se acomodam em um espaço de adultez jovem, que é indefinido e heterogêneo (BRITTO DA MOTTA, 2012b).

Ao afirmarmos que as sociedades ocidentais capitalistas elaboram uma noção ideal de adulto, na qual se atinge o auge de humanização, ressaltamos que isso se 
reflete no mercado de trabalho, que, de modo geral, prioriza essa geração, cuja faixa etária pode variar a depender dos contextos histórico, geográfico e social'. A essa regra, porém, há ressalvas notórias ao senso comum, a exemplo das carreiras de modelo, cuja aposentadoria é extremamente precoce, antes mesmo de atingida a fase adulta em sua plenitude, excetuando-se raros casos, nos quais homens e, sobretudo, mulheres conquistaram renome internacional. Entretanto, há, ainda, outras poucas carreiras que estendem a compreensão de idade produtiva do sujeito. É nesse rol que entendemos que se encontra a carreira acadêmica.

Alguns são os fatores que conciliam a academia e as gerações mais velhas. Um importante é o grande número de requisitos tidos como mínimos para o ingresso nessa carreira, uma vez que a regra é de ao menos mais seis anos de formação, correspondentes aos cursos de pós-graduação stricto sensu de mestrado e doutorado, para que se tenha um profissional pleno, apto à pesquisa e à docência. Isso faz com que a idade mínima para o ingresso na carreira seja maior do que em outras profissões, estendendo, também, a idade de afastamento das atividades, não sendo incomum a permanência de docentes que já cumpriram os requisitos para a aposentadoria. Podemos falar, também, da natureza intelectual do trabalho, que faz com que esse pareça estar em maior conformidade com os estereótipos de fraqueza e debilidade física associados à velhice.

Quanto ao interesse do/a pesquisador/a em permanecer nas atividades acadêmicas mesmo após a aposentadoria, é preciso entender os conceitos de capital científico e autoridade científica, trabalhados por Pierre Bourdieu (1983b). Para o autor, a carreira tem como "moeda" mais importante um capital simbólico, que ele denomina de capital científico. Sinteticamente, é a partir da aquisição e da acumulação desse capital que se alcança a autoridade científica e, portanto, o reconhecimento dos pares-concorrentes. Desse modo, a permanência em atividade é indispensável para a conquista ou manutenção desse capital. Isso é, ainda que não esteja sendo remunerado/a para continuar em atividade após a aposentadoria, o/a pesquisador/a permanece disputando a "remuneração" mais importante do campo científico, de natureza simbólica, que é o capital científico.

No mais, é preciso salientar que a maior afinidade com a absorção do trabalho de pessoas idosas não faz da academia um espaço democrático. Ao contrário, é um campo de disputa de poder e exercício de privilégios e, por isso, bastante excludente, no qual são reproduzidas as tensões e desigualdades presentes nas relações sociais. Desse modo, diversos grupos, como pessoas negras, indígenas, com deficiência, transexuais e travestis, são alijados da carreira acadêmica, especialmente por recaírem sobre seus corpos estereótipos não condizentes com as noções eurocêntricas e ocidentais de intelectualidade, e, sobretudo, de humanidade, sendo vistos como destituídos dos atributos tidos como essenciais para o ingresso na academia.

Assim, é paradoxal que, inobstante a carreira acadêmica ser uma exceção dentro do contexto do mercado de trabalho numa sociedade submetida ao sistema capitalista, ela contempla um perfil bem específico de pessoas, o que, em si, determina quais velhos/as serão prestigiados/as com uma extensão socialmente e economicamente reconhecida da vida profissional acadêmica. Para Frantz Fanon (2008, p. 44), os negros são submetidos a um "[...] arsenal de complexos germinados no seio de uma situação colonial [...]", cujos desvios os colocam num lugar de suspeição, pois foram sendo escravizados/as, também, pelos seus arquétipos. 
Não estamos exagerando: um branco, dirigindo-se a um negro, comporta-se exatamente como um adulto com um menino, usa a mímica, fala sussurrando, cheio de gentilezas e amabilidades artificiosas. Não observamos este comportamento em apenas um branco, mas em centenas [...] (FANON, 2008, p. 44).

Esse processo de "infantilização", do qual Fanon (2008) faz referência, também está presente nas outras relações de opressão social e está diretamente relacionada à subtração da capacidade intelectual do sujeito oprimido. Isso se dá com o apagamento das memórias, das expressões e do conhecimento de diversos grupos sociais, como as mulheres - de todas as raças e etnia, embora em contextos diversos -, os/as negros/as, as travestis, os/as transexuais, as pessoas com deficiência, os/as velhos/as e, ainda, com as próprias crianças. Desumanizados, esses corpos deixam de pertencer a seres pensantes e, como consequência óbvia, os conhecimentos que produzem deixam de ser válidos e não são legitimados em quaisquer esferas da vida cotidiana e isso se reflete, de forma maximizada, na academia. Estamos diante de um apagamento epistêmico sistematizado, que valida enquanto ser universal o homem adulto branco cisgênero heterossexual, colocando-o no centro, e no topo, das produções acadêmicas. Eles formam o que Patricia Hill Collins (1990) chama de "elites cultas", que são aquelas que acreditam que são as únicas qualificadas para produzir teorias, podendo, inclusive, interpretar, além da sua própria, as experiências dos outros.

Ainda nesse sentido, e falando especificamente sobre as mulheres negras na academia, Hill Collins (2016) assevera que as intelectuais negras possuem um status de forasteiras de dentro (outsider whitin) e compõem um dos diversos grupos de marginais intelectuais, cuja postura crítica é essencial para a produção de conhecimento. Se a academia se construiu, historicamente, como um espaço culturalmente homogêneo ${ }^{2}$, tensionar essa instituição com o ingresso de outros sujeitos, mormente a partir de novas propostas epistemológicas, é tarefa das mais importantes.

No tocante à relação entre pesquisadoras/es trans e a produção de conhecimento acadêmico, viviane Vergueiro (2016), em dissertação de mestrado auto etnográfica, destaca a experiência, os questionamentos e as tensões de ser uma mulher trans pesquisadora na academia, de falar a partir desse lugar e, sobretudo, de falar sobre esse lugar.

Gradualmente, assim, fui sentindo que, para produzir um trabalho acadêmico crítico sobre diversidades corporais e de identidades de gênero, implicar minhas próprias experiências e refletir sobre como minha subjetividade enquanto pesquisadora trans se constituíam como requisitos fundamentais, particularmente em um contexto em que exclusões e marginalizações de pessoas trans* e gênero-diversas restringem as complexidades destas existências. (VERGUEIRO, 2016, p. 22).

Assim, é tendo ciência da complexidade da academia enquanto espaço de poder e, pois, de disputas políticas, econômicas e epistemológicas, que trabalharemos com a interface dessa carreira com a categoria geração, a partir dos dados públicos relativos à permanência em atividade de docentes aposentados/as, por meio do Programa Especial de Participação de Professores Aposentados PROPAP, extraídos Relatórios de Gestão 2017 das unidades da UFBA. 


\section{APOSENTADORIA E PERMANÊNCIA: O CASO UFBA}

A docência e a pesquisa acadêmicas, como vimos, escapa um pouco da curva geracional comum às outras carreiras. Alguns/mas velhos/as, até um certo limite etário, se coadunam com os valores, caros à academia e à ciência, de intelectualidade, maturidade e conhecimento, que, muitas vezes, são contraditórios aos estereótipos vinculados à juventude e adultez jovem. Para ilustrar o que argumentamos ao longo desse trabalho, traremos dados empíricos produzidos a partir dos Relatórios de Gestão exercício 2017 das unidades da UFBA, no tocante às solicitações de permanência de docentes aposentados/as nos Programas de Pós-Graduação da instituição, por meio do Programa Especial de Participação de Professores Aposentados - PROPAP.

Antes da apresentação nos dados, cumpre salientar que a escolha pelos Relatórios de Gestão se deu por ser o único documento público da UFBA que traz, ainda que parcialmente, informações acerca da adesão de docentes aposentados ao PROPAP, haja vista que tais dados, bem como os referentes às aposentadorias, não constam no boletim de pessoal da Coordenação de Gestão de Pessoas (CGP), disponibilizado no sítio eletrônico da Pró-Reitoria de Desenvolvimento de Pessoas (PRODEP) da UFBA. Desse modo, não nos restou alternativa senão a análise dos Relatórios de Gestão exercício 2017 das vinte e sete unidades da Instituição.

Ademais, vale destacar que o número de docentes vinculados ao Programa Especial de Participação é subestimado nos relatórios, haja vista que não é dado obrigatório a ser incluído, não significando, pois, que as unidades que não declararam no Relatório de Gestão 2017 a existência de docentes aposentados/as em atividade pelo PROPAP não contam com a efetiva participação deles/as no quadro de seus programas de Pós-Graduação. Assim, o uso dessa fonte nos serve de indicação para pensarmos a continuidade da carreira docente, em especial na UFBA, mesmo após a aposentadoria e a ruptura do vínculo empregatício, oferecendo um número mínimo de professores/as aposentados/as que se mantêm ativos/as, em alto nível acadêmico, que deverá ser comprovado, no momento da proposição ao Departamento interessado e, posteriormente, à Câmara de PósGraduação e Pesquisa do Conselho de Coordenação da participação do/a docente no PROPAP, com a apresentação de produções técnica, científica ou cultural dos últimos cinco anos (BRASIL, 1996).

Isso posto, das vinte e sete unidades integrantes da UFBA, apenas cinco fizeram constar em seu Relatório o número de professores/as aposentados/as que se mantêm em atividade por meio do PROPAP, havendo, nessas poucas unidades e no ano de 2017, ao menos dezenove docentes que, sem vínculo empregatício com a Instituição, recebem a denominação de Professor Participante Especial, podendo exercer atividades de pesquisa, orientar estudantes/pesquisadores/as e ministrar aulas nos cursos de Pós-Graduação, dentre outras atividades inerentes à carreira do magistério superior. Dentre as unidades que declararam, a maior concentração de aposentadas/os em atividade está na Faculdade de Medicina, na qual nove docentes participam do PROPAP. Cabe destaque também para o Instituto de Letras, que, inobstante não ter listado ou quantificado todos/as os/as docentes participantes do PROPAP, fez constar em seu relatório, no item de atividades de pesquisa, dois projetos interinstitucionais, sendo um deles, o Projeto Atlas Linguístico do Brasil (ALiB), coordenado por quatro docentes mulheres, das quais duas são aposentadas e vinculadas à Pós-Graduação. 
É notório, pois, que a participação de docentes aposentados/as é bastante relevante para as atividades acadêmicas, em especial nos níveis mais altos de produção científica. Nesse sentido, trazendo também um recorte de gênero aos dados produzidos a partir da realidade Universidade Federal da Bahia em dezembro de 2018, é expressivo o número de mulheres bolsistas de produtividade CNPQ aposentadas que atuam na instituição. Das 79 (setenta e nove) docentes contempladas nos diversos níveis da bolsa, 23 (vinte e três) delas, quase $30 \%$ (trinta por cento) portanto, são aposentadas, o que comprova que, além de ser o campo acadêmico um espaço mais receptivo às mulheres idosas aposentadas, a atuação delas é de extrema relevância para a manutenção para a produção de conhecimento científico.

\section{CONSIDERAÇÕES FINAIS}

O mercado de trabalho tem sido, historicamente, excludente, contemplando, especialmente nos postos de maior prestígio, um perfil bastante restritivo e homogêneo de trabalhadores/as, normalmente homens adultos brancos de classes sociais privilegiadas. Entretanto, a carreira acadêmica tem se destacado como uma exceção na qual uma dessas variáveis, a adultez, tem sido relativizada, sendo, com isso, contemplados docentes velhos/as, mesmo os/as já aposentados/as. Muito disso se dá porque grande parte dos estereótipos relacionados à velhice não alcançam a carreira acadêmica, em especial no tocante aos/às velhos/as recém aposentados/as, a exemplo da falta de força física e da fragilidade da saúde. Ademais, esses sujeitos estão alinhados com muitos dos valores tidos como primordiais para a produção ciência e o ensino, como as noções de intelectualidade, acúmulo de experiência e maturidade. Além disso, é de interesse dos/das pesquisadores/as se manterem ativos/as, haja vista que a luta pela aquisição de capital científico não cessa com a aposentadoria, permanecendo a disputa no campo científico para a conquista do reconhecimento pelos pares, que são, ao mesmo tempo, concorrentes e os únicos capazes de conferir a autoridade científica.

Há, portanto, uma extensão da faixa etária vista como legítima para o trabalho na academia, em relação à média de outras carreiras, que não se aplica, contudo, a todas as minorias políticas, tampouco denotam um processo de democratização do espaço universitário. Desse modo, a flexibilização da indispensabilidade da adultez como traço que capacita, ou não, um indivíduo para um determinado trabalho não alcança todos/as os/as velhos/as, não contemplando, como regra, por exemplo, pessoas trans, não brancas, com deficiência, mulheres etc., que continuam a ser sub-representadas nesse espaço, em maior ou menor grau.

Com o objetivo de estudar e compreender a dinâmica desse alargamento das idades limites para o exercício da carreira docente, relacionamos os aportes teóricos com os dados empíricos produzidos e percebemos que a UFBA não foge à regra, tendo aprovado, em 1996, resolução que instituísse o Programa Especial de Participação de Professores Aposentados nas atividades de pesquisa e de ensino da instituição. A universidade é, assim, um espaço de produção de conhecimento científico-acadêmico que prevê a permanência dos/as professores/as aposentados/as na docência, ainda que sem vínculo empregatício e sem remuneração financeira específica, para evitar a descontinuidade de atividades já iniciadas, especialmente em setores de pesquisa e na Pós-Graduação e por meio 
de dinâmicas que reproduzem as desigualdades sociais observadas fora da academia. 


\title{
Academic career: paradoxes and tensions from the lens of gender and generation
}

\begin{abstract}
Age is important variable for the labor market, being, as a rule, privileged to adulthood as a stage of life in which the subject is fully fit to enter and stay in the so-called productive spaces. However, this does not take place in a homogeneous way, since there are careers, such as academic ones, that bring specificities, valuing more or less the presence of old people. In this sense, with the objective of analyzing how the age group enlarges in the teaching career, this article will focus on the data produced from the 2017 Management Reports of the units of the Federal University of Bahia, which registered part of the teachers who participate in the Special Program for the Participation of Retired Teachers, established by Resolution n. 4/96. These data point to the continuity of the researcher in the institution, even after old age, due to the importance of scientific capital, directly related to recognition.
\end{abstract}

KEYWORDS: Academic career. Teaching. Generation. Old age. Scientific field.

\section{Carrera académica: paradojas y tensiones desde la óptica de género y generación}

\author{
RESUMEN
}

La edad es una variable importante para el mercado laboral, siendo, por regla general, privilegiada a la edad adulta como etapa de la vida en la que el sujeto está en plena forma para ingresar y permanecer en los llamados espacios productivos. Sin embargo, esto no se lleva a cabo de manera homogénea, con carreras, como las académicas, que aportan especificidades, valorando más o menos la presencia de personas mayores. En este sentido, con el objetivo de analizar cómo aumenta el grupo de edad en la carrera docente, este artículo se centrará en los datos producidos a partir de los Informes de Gestión 2017 de las unidades de la Universidad Federal de Bahía, que registraron parte de la / los maestros que participan en el Programa Especial para la Participación de Maestros Retirados, establecido por la Resolución n. 4/96. Estos datos apuntan a la continuidad del investigador en la institución, incluso después de la vejez, debido a la importancia del capital científico, directamente relacionado con el reconocimiento.

PALABRAS CLAVE: Carrera académica. La enseñanza. Generación. La vejez. Campo cientifico. 
${ }^{1}$ Sobre a construção social das noções de velho e jovem, cabe ressaltar a compreensão de Bourdieu (1983a), que afirma: "Quando digo jovens/velhos, tomo a relação em sua forma mais vazia. Somos sempre o jovem ou o velho de alguém. É por isto que os cortes, seja em classes de idade ou em gerações, variam inteiramente e são objeto de manipulações. [...] O que quero lembrar é simplesmente que a juventude e a velhice não são dados, mas construídos socialmente na luta entre os jovens e os velhos. As relações entre a idade social e a idade biológica são muito complexas." (BOURDIEU, 1983a, p. 2).

${ }^{2}$ Sobre isso, é elucidativo o depoimento da educadora feminista negra bell hooks. "Frustrada, comecei a questionar os modos pelos quais os preconceitos racistas e sexistas moldavam e informavam toda a produção acadêmica que tratava da experiência negra e da experiência feminina. Estava claro que esses preconceitos haviam criado uma circunstância onde havia pouca ou nenhuma informação sobre as experiências características das mulheres negras." (HOOKS, 2017, p. 163).

\section{REFERÊNCIAS}

BOURDIEU, Pierre. A "juventude" é apenas uma palavra. In: BOURDIEU, Pierre. Questões de sociologia. Rio de Janeiro: Marco Zero, 1983a.

BOURDIEU, Pierre. O campo científico. ORTIZ, Renato (org.). Bourdieu -Sociologia. São Paulo: Ática. Coleção Grandes Cientistas Sociais, v. 39. p. 122-155, 1983 b.

BRASIL. Resolução n. 04, de 18 de julho de 1996. Institui o Programa Especial de Participação de Professores Aposentados nas atividades de pesquisa e de ensino de Pós-Graduação na UFBA. Disponível em: <http://www.ppglinc.letras.ufba.br/sites/ppglinc.letras.ufba.br/files/Resolu\%C3\% A7\%C3\%A30\%20PROPAP\%20UFBA.pdf> Acesso em: 22 de agosto de 2018.

BRITTO DA MOTTA, Alda e WELLER. Wivian (orgs). A Atualidade do Conceito de Gerações na Pesquisa Sociológica. Dossiê. Revista Sociedade e Estado. UNB, Brasília, v. 25, n. 2, p. 175-184, 2010.

BRITTO DA MOTTA, Alda. A geração pivô, intermediária na família. In: XV Encontro de Ciências Sociais do Norte e Nordeste e Pré ALAS Brasil. Anais..., Teresina: UFPI, 2012a.

BRITTO DA MOTTA, Alda. A Juvenilização atual das idades. Revista Caderno Espaço Feminino. Uberlândia, v. 25, n. 2, p. 11-24, 2012b.

BRITTO DA MOTTA, Alda. As dimensões de gênero e classe social na análise do envelhecimento. Cadernos Pagu, UNICAMP, Campinas, n. 13, p. 191-221, 1999. (Dossiê Gênero em Gerações).

BRITTO DA MOTTA, Alda. Teoria de Gerações na perspectiva de gênero. In: Maria Helena Santana Cruz; Amy Adelina Alves. (Org.). Feminismo, Desenvolvimento e Direitos Humanos. 1 ed., v. 1, Aracaju, 2005. 
COLLINS, Patricia Hill. Aprendendo com a outsider within*: a significação sociológica do pensamento feminista negro. Revista Sociedade e Estado. Vol. 31, n. 1, p. 99-127, 2016.

FANON, Frantz. Pele negra, máscaras brancas. Bahia: Editora Edufba, 2008.

GRÜN, Roberto. Conflitos de geração e competição no mundo do trabalho. Cadernos Pagú, Campinas, n.13, p. 63-107, 1999.

HILL COLLINS, Patricia. Black feminist thought: knowledge, consciousness and the politics of empowerment. 2nd ed. New York: Routledge, 2000.

HOOKS, Bell. Ensinando a transgredir: a educação como prática de liberdade. 2 ed., São Paulo: WMF Martins Fontes, 2017.

LENOIR, Remi. Objeto sociológico e problema social. In: CHAMPAGNE, Patrick; LENOIR, Remi; MERLLIÉ, Dominique. Iniciação à prática sociológica. Petrópolis: Vozes, 1998

MACEDO, Márcia dos Santos. Geração e mulheres chefes de família: algumas notas de pesquisa. In: ALVES, Ivia; VASQUEZ, Petilda; SCHEFLER, Maria de Lourdes; AQUINO, Sílvia de. (Org.). Travessias de gênero na perspectiva feminista. Salvador: EDUFBa, 2010.

MANNHEIM, Karl. Sociologia do Conhecimento. Porto, Portugal: Res Editora, [s.d.].

MÜLLER, Elaine - Repensando a problemática da transição à adultez. Contribuição para uma Antropologia das Idades. Política e Trabalho. Revista de Ciências Sociais. n, 31, p. 107-125, 2009.

PEÇANHA, Eline G. F. E.; MOREL, Regina. Gerações Operárias: rupturas e continuidades na experiência de metalúrgicos do Rio de Janeiro, n. 17, RBCS, 1991.

SARMENTO, Manuel Jacinto. Gerações e alteridade: interrogações a partir da sociologia da infância. Educação e Sociedade, Campinas, v. 26, n. 91, p. 361-378, 2005.

SCOTT, Parry. Quase adulta, quase velha: por que antecipar as fases do ciclo vital? Revista Interface, v. 5, n. 8, p. 61-72, 2001.

VERGUEIRO, viviane. Por inflexões decoloniais de corpos e identidades de gênero inconformes: uma análise autoetnográfica da cisgeneridade como normatividade. Dissertação de mestrado. Salvador: Universidade Federal da Bahia, 2016. Programa Multidisciplinar de Pós-graduação em Cultura e Sociedade/ Instituto de Humanidades, Artes e Ciências Professor Milton Santos. Universidade Federal da Bahia. 
Recebido: 15/03/2019.

Aprovado: 22/07/2019.

DOI: $10.3895 /$ cgt.v12n40.9847.

Como citar: FARIA, lolanda Pinto de. Carreira acadêmica: paradoxos e tensões a partir das lentes de gênero e geração. Cad. Gên. Tecnol., Curitiba, v. 12, n. 40, p. 295-309, jul./dez. 2019. Disponível em: https://periodicos.utfpr.edu.br/cgt. Acesso em: XXX.

Correspondência:

lolanda Pinto de Faria

Rua Oito de Dezembro, n. 808, ap. 704, Graça, Salvador, Bahia, Brasil.

Direito autoral: Este artigo está licenciado sob os termos da Licença Creative Commons-Atribuição 4.0

Internacional.

(c) (1) 